Specialty care in the community

\title{
Providing specialist services in the community
}

\section{J F Mayberry}

The political imperative for changing healthcare delivery in the UK

n recent issues, the Postgraduate Medical Journal has explored the concept of specialty care in the community. With the present drive towards providing local, specialised care for patients with chronic diseases the need for a new type of specialist is self-evident. Such specialists will need to be based in the community and, in addition to delivering treatment, they will be expected to promote healthier lifestyles. Clearly, an organised approach to health improvement is critically important in an age when obesity, sexually transmitted diseases and cardiovascular diseases are major sources of morbidity. Education of patients is a core element of successful treatment, but educating people so as to prevent the development of illness is a much more effective approach.

During the 21st century, clinicians with a specialist interest will need to take proactive steps to help ensure a healthy population. For the vast majority this will be a new aspect of their work, but one that is ideally suited to a professional practice based in the community.

This issue of the Journal brings together comments from leading politicians and the Chief Medical Officer. Their combined views confirm the need for a new approach to specialist care and treatment-one that will be flexible and based in the community.

Postgrad Med J 2007;83:2.

doi: $10.1136 /$ pgmi.2006.056028

Correspondence to: John Mayberry, Editor, Postgraduate Medical Journal, Leicester General Hospital, Gwendolen Road, Leicester, LE5 4PW, UK; pmi@bmigroup.com

\section{Delivery of healthcare outside acute hospitals: the Rt Hon David Cameron MP, Leader of the Conservative Party and Leader of the Opposition}

\section{The need to invest in training}

$\mathrm{P}$ atients and their carers are very clear that they want to see healthcare delivered wherever possible at home or in homely settings in the community. Medical advances now mean that we are able to deliver far more healthcare outside acute hospitals and this is a trend that is likely to continue.

Although the number and range of general practitioners with special inter- ests has been disappointing, many family doctors have extended their skills so that they are able to offer services to patients that would previously have been available only from a hospital specialist. However, this should not be seen as an opportunity to provide specialist care on the cheap and special interests must not dilute the discipline of general practice. It is a gem within our National Health Service (NHS) and firmly established as a specialty in its own right.

Today's medical graduates are far more aware than their predecessors of the importance of healthcare outside teaching hospitals. Hospital specialists generally welcome the prospect of seeing patients in the community and itinerant clinics promote closer working between primary and secondary care. However, specialist care in the community requires premises to operate from and the current programme of community hospital closures seems an odd way to promote it.

Specialty care in the community is unlikely to flourish while postgraduate deans have their training budgets raided to remedy NHS deficits. Disinvesting in training today means a de-skilled and demoralised workforce tomorrow.

So there is great potential to offer more healthcare at home or in homely settings, but the Government needs to make sure its policies keep up with medical advances and with the changing expectations of patients and their carers.

Postgrad Med J 2007;83:2.

doi: 10.1136/pgmi.2006.056085 